\title{
Dürer e o Tema da Melancolia'
}

\author{
Andreia de Freitas Rodrigues ${ }^{2}$
}

\section{Resumo}

O texto procura analisar a construção de um modelo iconográfico na história da arte, pensando a trajetória histórica das representações da melancolia desde a antiguidade, chegando até a gravura Melencolia I produzida por Albrecht Dürer em 1514, e que estabeleceu o que poderíamos considerar como um autêntico paradigma representacional. Tal obra pode ser tomada como ponto iniciático e fio condutor do artigo, que tenta demonstrar possíveis fontes e inspirações do artista alemão, além de propor breve reflexão sobre algumas interpretações dadas à Melencolia I.

Palavras-chave: Melancolia. Modelo. História da Arte.

Abstract

The text attempt to analyze the development of an iconographic model in the history of art, considering the historical condensed on the engraving Melencolia I produced by Albrecht Dürer in 1514. This engraving could be considered a paradigm. This work is the starting point and guideline of the article, which tries to demonstrating sources and inspiration of the German artist, besides offering a brief reflection on some interpretation on the Melencolia I.

Keywords: Melancholy. Model. Art History. 
A trajetória da melancolia e sua ambígua tradição, como sabemos, é longa. Remonta à Antiguidade Clássica e encontra na gravura Melencolia I (figura 1), de Albrecht Dürer, um completo exemplo de representação do tema e provável síntese da filosofia de Marsilio Ficino, principalmente do De vita triplici: a retomada das ideias neoplatônicas e a concepção melancólica de Aristóteles, fonte de inspiração regida pelo temperamento negro e bilioso, atribuído ao planeta Saturno, amparada por conhecimentos mágicos e astrológicos, matemáticos e geométricos, médicos e alquímicos. Também está na obra de Ficino toda a sorte de recursos para a proteção dos efeitos nocivos causados pela afecção melancólica, o que incluiu a manufatura de amuletos e poções, a música astral ou a magia celeste. Melencolia I apresenta uma poderosa concordância entre uma ideia e uma imagem concreta, o que a torna um marco referencial para as representações do humor melancólico, que permanece até os dias atuais ${ }^{3}$.



Figura 1 :: Melencolia I - Albrecht Dürer - Buril, 1514. 239 × 168mm.2 cópia - $2^{\circ}$ tiragem. Vevey. Musée Jenisch, Cabinet cantonal des Estampes (fundo Pierre Decker) inv. DK31 (Decker 75lla).

Fonte :: CLAIR, 2005, p. 139. 
As observações baseadas na gravura propriamente dita, aqui apresentadas, em todos os seus elementos, procuram refazer o percurso do artista, como uma montagem ou colagem de referências em relação ao tema, e trabalham para a introdução das interpretações sobre a gravura alemã, tentando discernir o significado que o artista quis dar ao trabalho. Não se destina a um julgamento de entendimento, do certo ou errado, mas antes, tem a intenção de iniciar, plantar uma semente, nesse aparentemente interminável campo de interpretações da gravura de Albrecht Dürer.

\section{A gravura}

Datada de 1514, a gravura em cobre tem registrado em letras capitais seu nome Melencolia I, não deixando dúvidas de que se trata da ilustração do temperamento saturnino. Imersa em um ambiente obscuro, surge a figura central, trazendo na cabeça uma coroa de plantas aquáticas e longas asas. A solidez de seu corpo, reforçada pela opulência de suas vestes, de onde pendem um conjunto de seis chaves e uma bolsa, impõe um peso e imobilidade que torna impossível seu voo. A cabeça está apoiada sobre o punho esquerdo, cerrado. Traz no colo um livro fechado e segura displicente, com a mão direita, um compasso que nada mede, enquanto seu olhar vazio parece se dispersar para além da gravura, na distância de toda a meditação que a absorve.

Ao seu redor um incrível conjunto de objetos está espalhado, tornando a composição um imenso repositório de ruínas que se acumulam desordenadas, aparentemente. A melancolia permanece indiferente a todos eles. Aos seus pés, encontram-se pregos e cravos, um formão, uma régua, um serrote, um martelo, um tinteiro e um cadinho. Parcialmente escondidos sob a saia, estão um alicate e um fole. Uma esfera repousa à frente do cão que dorme desavisado, ao lado do anjo.

Logo atrás das paredes de uma construção inacabada, pendem uma balança, uma ampulheta, um sino e um quadrado mágico. Também apoiada na parede do edifício sem janelas, está uma antiga roda de moinho 
e acomodado sobre ela em um tapete, um putto, que parece bastante ocupado em sua tarefa de escrever, tornando-o alheio a toda cena que se desenrola. Uma escada de sete degraus se apoia inclinada na construção e emoldura a visão de um pequeno lugarejo que se configura distante. Um bloco de pedra irregular, habilmente esculpida em oito lados, equilibra-se adiante, obstruindo parcialmente a visão da paisagem marítima que se abre mais abaixo, trazendo uma pequena embarcação. Acima do horizonte um cometa corta o céu, iluminando o arco íris que envolve o morcego, com cauda de dragão, que segura em suas asas o emblema Melencolia I. No canto inferior direito, cravado na pedra do piso externo onde está sentado o anjo, está o ano da gravação e as iniciais de seu nome, monograma característico de Albrecht Dürer.

\section{A iconografia}

Raymond Klibansky, em 1989, ao escrever a nota introdutória da versão francesa de Saturno e Melancolia, advertia sobre a quantidade de publicações relacionadas a essa obra. "A quantidade de escritos é proporcional à dificuldade das explicações" (KLIBANSKY; PANOFSKY; SAXL, 2004) $)^{4}$

Construída como um "programa de arte visual", a gravura constrói uma longa tese sobre a teoria da arte, que assume pelo menos um entre diversos aspectos como, por exemplo, a melancolia como autorretrato espiritual do artista ou a personificação do humor hipocrático melancólico nas artes visuais ou como modelo de representação da geometria, uma das sete artes liberais. A dificuldade em analisar a gravura está em considerar então, um dos aspectos diferentes ou nenhum deles ou todos eles, localizados na polissemia de seus significados.

O modelo que apoia a cabeça na mão é antigo, aparece em sarcófagos e estelas funerárias, significando tristeza e luto, mas também está associado ao cansaço e à loucura, como em representações de Ajax ou Belerofonte, heróis gregos ou Saul, o atormentado rei de Israel. Durante a 
Idade Média, esse modelo esteve quase abandonado, contudo, manteve-se em representações de São João, como por exemplo, o santo pintado por Giotto, aproximadamente em 1320 na Capela de Santa Croce, em Florença ou em representações de Saturno. No Renascimento, influenciada pela ideia do gênio melancólico aristotélico, a clássica posição foi retomada em diferentes trabalhos:

Ao melancólico dos manuscritos e gravuras germânicas posando com a cabeça sobre a mão, responde, na Itália, por um lado, a figura de Heráclito, na Escola de Atenas de Rafael, e, por outro, Saturno numa gravura de Campagnola: eis a encarnação majestosa da contemplação de um Deus, o que apenas mais tarde influenciaria os retratos da contemplação humana em geral (KLIBANSKY; PANOFSKY; SAXL, 2004, p. 452).

Contudo, os primeiros conceitos dados à melancolia são atribuídos a Hipócrates (460 - 377 a.C.), que no Aforismo 23 do livro VI a define como tristeza e medo de longa duração: "Se o medo e a tristeza duram muito tempo, tal estado é próprio da melancolia" (BERLINCK, 2008). Para o médico de Cós, a bile negra, um dos quatro humores presentes no corpo humano, incide diretamente sobre o baço, numa manifestação fisiológica que caracteriza a melancolia. Hipócrates atribuiu à bile negra correspondências com as estações do ano (outono), etapas da vida (velhice), elementos da natureza (terra). Mais tarde, a relação do humor com os planetas fez com que a melancolia fosse associada à Saturno. Galeno de Pérgamo (129 200) sintetizou os conhecimentos médicos surgidos ao longo dos cinco séculos anteriores, relacionando os humores aos tipos físicos e disposições emocionais: o melancólico seria magro, pálido, taciturno, noturno, lento, avarento, invejoso, solitário. Mas foi o fundador da escola médica de Salermo, Constantinus Africanus (1010 - 1087) que traduziu para o latim, a partir do árabe, a obra dos médicos gregos, conservando as concepções desses autores. No início de seu livro "De melancholia", lê-se:

Os acidentes que a partir dela [da melancolia] sucedem na alma parecem ser o medo e a tristeza. Ambos são péssimos porque confundem a alma. Com efeito, a definição de tristeza é a perda do muito intensamente 
amado. O medo é a suspeita de que algo ocasionará dano (KLIBANSKY; PANOFSKY; SAXL, 2004, p. 100-101).

A perda induz a tristeza, os melancólicos estão em um lugar do qual veem com sofrimento o passado, em razão de perdas e se perturbam com o futuro, pelo medo de outro possível dano.

Os desenhos encontrados representando os quatro humores ou temperamentos (como no livro das horas francês de Robinet Testard, de 1447) trazem a figura da melancolia como descrita por Hipócrates ou Galeno: geralmente um velho magro, com uma bolsa e/ou moedas (o avarento), solitário e, por vezes, com a cabeça apoiada na mão.

Para Aristóteles (384 - 322 a.C), não apenas os heróis trágicos, mas sim todos aqueles que se destacavam no domínio das artes, da poesia, da filosofia e da política, estavam marcados pela melancolia. $O$ sentimento bilioso que ele evoca não era uma doença, mas sim a própria natureza dos filósofos, o seu ethos (sua moral). A proposição atribuída a Aristóteles, levou à compreensão de que existiria uma ligação entre a postura melancólica e o pensamento contemplativo necessário para a filosofia (KLIBANSKY; PANOFSKY; SAXL, 2004, p. 39-57).

É em Problema XXX (ARISTÓTELES, 2008), um dos trinta e oito livros curtos que compõe Problemas, em que Aristóteles, tratando do pensamento, da sabedoria e da criação, influenciou a interpretação do gênio humano mais do que todos os outros escritos. Sua obra, aliás, seria uma daquelas que, sem se destacar por seu estilo ou pela densidade de pensamento, mantém sua fulguração inalterada: "Um sentimento de familiaridade nos liga a [obras como essa]", afirma o filólogo Jackie Pigeaud, para quem tais obras falariam de "evidências, ou antes, de ideias que recebemos não sabemos mais de onde [...] narram lugares-comuns de nossa própria cultura [...]" (PIGEAUD, 1998, p. 7).

Por volta dos séculos VIII e IX, buscou-se uma correspondência astrológica entre temperamentos e planetas, amparada por fontes árabes, que continham um sistema completo de coordenação: o temperamento sanguíneo se ligava a Vênus, o colérico com Marte, o fleumático com a lua. O melancólico foi, então, associado com Saturno e o deus Cronos, todos marcados por profunda dualidade. O planeta distante, de 
lenta movimentação, considerado entre os antigos o mais elevado no firmamento e por isso superior, extremo e frio, seria capaz de influenciar o desenvolvimento das capacidades incomuns.

Saturno é um planeta maligno, frio e seco, noturno e pesado e por isso, nas fábulas se apresenta velho. Seu círculo é o mais distante da Terra e ainda assim é o mais nocivo... Quanto à cor, é pálido, lívido como o chumbo, porque tem qualidades mortíferas, a saber, a frieza e a secura. Daí que o nascido ou concebido sob seu domínio, ou morrem ou tomam suas piores qualidades. Segundo Ptolomeu, em seu livro dos juízos, sobre os astros apresenta um homem feio, malfeitor, pesado, triste, raras vezes alegre ou risonho. (ANGLICUS, Bartolomeus. De propietatibus rerum, in: KLIBANSKY; PANOFSKY; SAXL, 2004, p. 191)

Para os gregos, Cronos é, por um lado, o deus benéfico da agricultura, que realiza festas nas colheitas; de outro, um deus sombrio, solitário, que vive na extremidade mais recolhida da terra, deus da morte e dos mortos. Pai dos deuses e dos homens, ele é capaz de devorar seus próprios filhos. A melancolia também tem uma especial relação com o tempo: para o melancólico, a temporalidade é quantificada, espacializada. O porvir se vê sempre relacionado ao passado. Também os neoplatônicos consideraram Saturno superior a Júpiter e a todos os outros planetas. Enquanto Júpiter simbolizava meramente a "alma" do mundo, aqueles que sabiam governar, Saturno simbolizava a "mente" e a inclinação para contemplação e investigação tanto das coisas consideradas celestes como daquelas consideradas terrenas (PANOFSKY, 2005, p. 180-181). Para a tradição cabalística, Saturno rege a esfera de "Binah", cuja cor é o negro e possui a faculdade da inteligência. Por isso os neoplatônicos atribuíram à Saturno o dom da sabedoria. Já a alquimia trata Saturno como símbolo do chumbo e da putrefação.

Assim, a posição do planeta Saturno, as atitudes de Cronos e as suscetibilidades da bile negra, oscilando entre graus intensos e opostos, fazem parte de uma articulação que confirma a vocação do melancólico para sentimentos extremos. 
Na Idade Média ocidental também surge o termo acedia ou acídia, desgaste ou perturbação do coração, doença normalmente verificada entre os monges e solitários, assim como os anacoretas que viviam próximos ao deserto de Alexandria. Era na plenitude da solidão que este acometimento, também considerado um pecado, configurava uma espécie de desolação naqueles que sofriam de seu mal, gerando uma inquietude quase paralisante e sonolência excessiva. Os textos religiosos acusam a acedia de ser uma das causas de um dos maiores pecados: a preguiça. A acídia estava associada à tristitia e à desperatio.

Em 1502, Albrecht Dürer (1471-1528) produziu sua primeira gravura em que trata do tema da melancolia, em uma alegoria de inspiração ainda medieval, que estampou o livro de Conrad Celtis, Quattuor Libri amorum. Ali a "Alegoria da Filosofia", está representada pelo vento boreal, o crepúsculo, a terra, o outono. Mas já trabalhava com a figura feminina desde 1495, com a "Pequena Fortuna", onde uma mulher se equilibra sobre a esfera e segura uma flor de cardo. Outra figura bastante semelhante está em "Sonho do doutor", de 1497-98, gravura onde também está um putto e novamente a esfera e em 1497 uma figura alada, masculina, é impressa em "Homem alado com roupa ideal tocando alaúde".

Mas foi em 1501-02, com a gravura "Nêmesis"5 ou a grande fortuna, que Dürer trabalhou a figura feminina alada que segura uma ampulheta e que também se equilibra sobre a esfera e flutua acima de uma cidade. Nêmesis está ligada à concepção de fortuna, divindade cega que distribuía sorte aos homens, a sorte pela circunstância, inconstância do destino, reflexão sobre o passado, lembrando as rodas da fortuna medievais, onde a alternância das circunstâncias, entre queda e ascensão, movimenta a vida das pessoas. Lembrando a correlação em algumas representações posteriores da melancolia (Os quatro temperamentos, de Virgil Solis, de 1514-62), a figura feminina estará acompanhada pelo ganso (na mitologia grega, para tentar fugir das investidas de Zeus, Nêmesis se transforma em gansa).

A coroa na cabeça da melancolia é composta por dois tipos de plantas aquáticas, hipérico ou erva de São João e valeriana, recordando as recomendações medievais do uso de emplastros úmidos sobre a testa 
daqueles acometidos pela afecção melancólica. As plantas ainda são usadas associadas, para o tratamento da depressão, sedação e indução ao sono.

O sino pendurado na parede atrás do anjo, presumivelmente, relaciona-se à aritmética e à música. A prescrição da música astrológica ou celestial servia para afastar a melancolia, assim como o rei Saul era acalmado pela música de Davi:

Ora, o Espírito do Senhor retirou-se de Saul, e o atormentava um espírito maligno da parte do Senhor [...] E quando o espírito maligno da parte de Deus vinha sobre Saul, Davi tomava a harpa, e a tocava com a sua mão; então Saul sentia alívio, e se achava melhor, e o espírito maligno se retirava dele. (Bíblia Sagrada, 1995, p. 256-257) ${ }^{6}$

A bolsa e as chaves presas à cintura da figura constituem o único elemento com referências escritas pelo artista alemão: "A chave significa poder, a bolsa, riqueza" (WAETZOLDT, 1950, p. 102), provável alusão à afirmação de que o poder deve ser conquistado. Cofres, moedas, bolsas são elementos recorrentes nas representações das figuras saturninas ou melancólicas, lembrando a avareza e riqueza associadas às descrições medievais do melancólico. Na mitologia antiga, Saturno (Cronos) era tido como guardião de tesouros e inventor da cunhagem de moedas. Na linhagem dos planetas era o mais poderoso. Muitas de suas representações medievais o trazem com bolsas, cofres ou moedas, mas nunca sem as chaves ${ }^{7}$.

Um dos objetos mais curiosos da composição é o quadrado mágico que aparece à direita da cabeça do anjo. Composto por quatro linhas entrecruzadas representa o quadro mágico de Júpiter (4/4), onde a soma das quatro casas, em qualquer direção, resulta 34. Dürer opera uma modificação na última linha, onde estão os números 15 e 14, formando o ano em que a gravura foi impressa, tornando o quadro um amuleto pessoal, onde o arranjo numérico, sob o signo de Júpiter, volta-se para a harmonia e a proteção de seu criador. Recordando o sentido elevado e simbólico de Saturno e as sutis energias que contém, além se seus aspectos negativos e das pesadas cargas que the aplicaram interpretações supersticiosas, este planeta mostrou que possui também distintas características opostas 
das coisas. Saturno é a lentidão e a sabedoria da velhice, a passagem para o estado purificador que precede a morte, representa o tempo, que devora os pequenos sucessos temporais, assim como devorava seus filhos, extinguindo em ambos os casos, aquilo que criou (KLIBANSKY; PANOFSKY; SAXL, 2004, p. 145-146).

A única figura ativa na gravura é o putto, e ele aparece para realizar alguma atividade, mas despreocupado, próprio a um ser apenas atarefado, de modo inconsciente. Ali está a influência de representações italianas, como um quadro perdido de Mantegna, Malancolia, de 1494, onde figuravam imagens de dezesseis putti músicos e dançarinos, bem próximas à figura de Dürer.

No horizonte distante, acima do mar, estão o arco-íris e o cometa. $O$ primeiro possui acepções antigas que remontam à Bíblia, quando Deus fez uma aliança com Noé, simbolizada pelo arco-íris, prometendo nunca mais inundar o mundo. As sete cores resultantes da dispersão da luz na água foram relacionadas pelo físico Isaac Newton (1642-1727) às sete notas musicais. Na mitologia grega, Íris era a deusa mensageira, que deixava atrás de si um rastro colorido. $O$ segundo, referência à astronomia, tem significações antigas que evocam o mistério e o mau presságio, acontecimentos infelizes (pestes, morte, fome). Estes elementos relacionam os universos terreno e celeste, como uma ponte entre eles.

Assim também é a escada, que conduz não ao topo do edifício inacabado, mas para cima, para o céu. Os diferentes aspectos do simbolismo da escada estão ligados às relações entre o céu e a terra. Na arte, a escada aparece como suporte imaginário da ascensão espiritual. É também o símbolo das permutas e das idas e vindas entre o céu e a terra. Seus sete degraus caracterizam outro simbolismo alquímico, onde cada degrau representa um dos sete metais e cada um dos corpos celestes associados.

A pedra esculpida em oito lados é uma referência à geometria descritiva cuja função principal era a construção matemática e perspectiva das figuras de faces múltiplas. Sendo o quadrado a representação da terra e o círculo a imagem do céu, o octógono era considerado a figura capaz de unir ambos, simbolizando o mundo intermediário, comunicação entre inferior e superior, entre terrestre e divino. 
O número oito, frequentemente relacionado com a morte e em particular com a morte iniciática, indica que a "passagem" terá que implicar na morte dos estados profanos e na ressurreição aos mundos superiores e, nesse sentido, o octógono simboliza uma verdadeira regeneração espiritual que supõe uma transmutação e um novo nascimento.

Tal como a magia, o nome e o poder de seu significado não são vãos e sem importância, mas, pelo contrário, uma ciência temível. Assim, o uso de nomes mágicos deveriam ser utilizados com prudência e circunspeção, cuja eficácia deriva de sua pronúncia em sua língua original, porque é precisamente o som o que atua. Permanecendo como um emblema, a legenda Melencolia I sob as asas de morcego corresponde a, além de um título, um lema. Dürer inovou na inscrição da melancolia substituindo o a pelo e, talvez pelo mesmo motivo que o fez criar um quadrado mágico personalizado 8 .

Dürer também produziu outras duas gravuras, que juntas à Melencolia I, formaram sua mais famosa tríade: São Jerônimo em sua cela, também de 1514 e O Cavaleiro, a Morte e o Diabo, de 1513. As três gravuras formariam uma unidade espiritual, correspondente à classificação escolástica medieval das virtudes, divididas em virtudes morais ( $\bigcirc$ Cavaleiro...), teológicas (São Jerônimo...) e intelectuais (Melencolia I), um conjunto plausível com a classificação dos três mundos: imaginatio, ratio e mens (KLIBANSKY; PANOFSKY; SAXL, 2004, p. 259). Provavelmente o número I, colocado após o nome, faz referência a esta categorização.

Morcegos, animais noturnos, pertencem ao universo de Saturno, enquanto cães pertencem ao planeta Júpiter. Morcegos são melancólicos, cães combatem a melancolia. O cão, fiel companheiro, espera adormecido, em um plano inferior ao morcego, advertência da influência dominante de Saturno sobre Júpiter, nesta obra.

E por fim, por toda composição, espalham-se objetos e instrumentos relacionados às atividades de peso, medida, construção, matemática e geometria9. No pensamento grego, a atitude melancólica foi associada à geometria e à ametria, isto é, a uma desproporção das medidas humanas, uma defasagem. Sem conseguir a simetria (suficiência), o melancólico é jogado na ametria (insuficiência). A confusão entre a sensibilidade 
melancólica e geométrica remonta ao planeta Saturno, em analogia à geometria e em geral, tudo o que se refere à medida do tempo, do espaço e suas aplicações. O geômetra, que trabalha com números é aquele que vive sob o império de Saturno.

As atividades geométricas, a ciência da perspectiva por exemplo, que supõe na pintura a ordenação das propriedades do espaço ou também a arte de construir, a arquitetura, que tanto se baseia na medida, no peso e na tensão dos materiais, são atividades que se situam sob o signo da melancolia.

A ação da bile negra acentua a fragilidade do sujeito melancólico, mas, por outro lado, constitui capacidades perceptivas incomuns. Estas estimulam o sujeito a transcender as limitações da normalidade. Dotado de dons que o elevariam, esse sujeito é impedido por suas limitações e impotências. Essa frustração é agravada pelo fato de o melancólico acreditar que o pensamento ordenado não o permite avançar até o absoluto. Num mundo em que a matemática é um saber importante, essa posição é paralisante. O melancólico vê o conhecimento inteiramente ordenado como ineficiente para seus propósitos, como adverte Olgária Matos:

[...] aliança entre geometria e melancolia tem uma longa tradição: aqueles dotados para a geometria são predispostos à melancolia, porque a consciência de uma esfera situada fora de seu alcance faz sofrer àqueles que têm o sentimento da limitação e insuficiência no plano do espírito. (MATOS, 1989, p. 152)

\section{As interpretações}

A gravura em metal de Dürer oferece algumas pistas sobre a complexidade e os paradoxos do tema da melancolia e ilustra sua natureza dialética: por um lado uma debilitante e paralisante força que pode levar à astenia, à inibição ou mesmo a uma doença mental; de outro lado, um estímulo criativo e uma reparadora potência capaz de libertar a criação 
artística e renovar sua vontade de sobrevivência. Dürer estabeleceu um modelo. Misturou à personificação de certo estado anímico, uma inclinação particular da sensibilidade e a encarnação em forma de alegoria de uma faculdade criadora da inteligência, o poder de pensar o mundo mais geometricamente. Confundindo, assim, em uma mesma figura, duas faculdades humanas não somente heterogêneas (uma afeição anímica e uma disposição da inteligência), mas também antinômicas, aqui a antiga inapetência espiritual que conduz à inatividade e ali, o contrário, uma faculdade mental voltada para a criação.

Há aproximadamente cem anos, Karl Giehlow ${ }^{10}$ propôs uma interpretação de Melencolia I, baseada no texto de Marsilio Ficino em De vita triplici em que dizia que, indivíduos sujeitos à influência planetária de Saturno são propensos à melancolia. Por seu excepcional talento, Dürer poderia ter reconhecido o seu próprio temperamento. Em uma breve nota de 1902, Giehlow tinha mostrado que muitas das características peculiares de Nemesis, estavam expostas em um poema escrito por Angelo Poliziano, Manto, entre 1480-1482, na introdução dos estudos sobre Virgílio. Ao comparar esse texto contra a gravura, Giehlow observou uma escrupulosa ilustração. Não seria Melencolia I a representação plástica do texto de Ficino?

A mistura entre a sensibilidade melancólica e a geométrica está relacionada com Saturno, o deus geômetra, administrador do tempo. Para Panofsky, esse é o sentido último da gravura de Dürer: as atividades ligadas à geometria, como a pintura e a arquitetura enquanto artes ligadas ao número e à medida, induzem naqueles que a praticam, uma imaginação melancólica. A figura resignada, afundanda em pensamentos, está percebendo as limitações do seu conhecimento. Klibansky, Panofsky e Saxl estudaram e escreveram, ao longo de cinquenta anos, a obra mais completa publicada sobre a melancolia, desenvolvendo seu caminho evolutivo desde a antiguidade. Acreditaram que a gravura representaria a frustração do gênio inspirado: a melancolia tem grandes asas, mas não voa e sofre com sua condição de gênio inativo e com a sensação de fracasso e inadequação. É criativo, porém incapaz de expressar sua visão, mesmo rodeado pelos instrumentos de sua arte. Tal como a filosofia oculta desde 
Pico della Mirandola em diante e tal como foi formulada por Agrippa de Nettesheim (1486-1535), incluindo o pensamento mágico e hermético do neoplatonismo de Ficino, a interpretação de Panofsky e seus colaboradores não lida com a categoria básica da magia, deixando de lado a dívida de Dürer para Ficino e seu De vita.

A independência reivindicada pelo artista Dürer era, frequentemente, incompatível com a sua fé religiosa. A geometria era a ciência por excelência tanto para Dürer como para o seu tempo. Assim, a elaboração da coleção de xilogravuras do artista foi inovadora, na medida em que deu destaque às imagens procedentes do universo religioso movidas por leis naturais. Dessa forma, Dürer promoveu a união do real com o imaginário em regras geométricas. Foi esse trabalho de criação e inovação artística que conferiu a Dürer a condição de primeiro pintor a elevar a descrição da melancolia à dignidade de um símbolo. Panofsky conclui, então, que Melencolia l é um reflexo da personalidade de Dürer.

É sabido que os argumentos históricos e filosóficos que orientaram a escrita de Saturno e a melancolia sofreram mudanças conceituais pelos longos anos em que foi escrito. Os autores viveram épocas de mudanças profundas, políticas e culturais, de violência humana, que acabaram por interferir no pensamento e logo, no texto, de modo que a visão negativa e o abatimento moral e físico surgiram na interpretação final da gravura alemã.

Se é possível acompanhar as imagens da Antiguidade Clássica, em seu caminho geográfico e histórico, é porque elas permanecem como tensão energética, como "vida em movimento", cujos traços mais significantes estão inscritos na memória da humanidade. Para Aby Warburg, o tempo da história não é simplesmente uma sucessão cronológica, mas valores expressivos que ganham força naquilo que chamou Pathosformeln, fórmula de pathos, onde se pode ver uma mímica intensificada da vida, uma gestualidade expressiva do corpo, com origem nas paixões e afecções sofridas pela humanidade. Cada época seleciona e elabora determinadas Pathosformeln, à medida das suas necessidades expressivas, regenerandoas a partir da energia inicial. É uma ideia que se aproxima de Jackie Pigeaud, quando comenta Aristóteles e o Problema XXX, 1. É assim que a Melencolia I de Dürer pode ser vista, na concepção de Warburg, não apenas como 
manifestação das forças mais obscuras e imobilizantes, mas também como a emergência da reflexão e do pensamento. A polaridade se torna uma categoria interpretativa de fenômenos culturais. Tudo tem uma relação bipolar: cultura antiga e moderna, cristã e pagã, pensamento mágico e lógico... Utiliza a linguagem de pathos heróico e teatral, expressão física intensificada: descoberta da dimensão dionisíaca do Renascimento, oposta à visão habitual de um Renascimento apolíneo onde triunfa a ordem, clareza e harmonia (GINZBURG, 1989, p. 45). Warburg atribuiu um profundo significado do humanismo italiano na obra de Dürer, como um elo na cadeia de transmissão do patético. O potencial criador humano seria a saída para vencer o potencial celeste da natureza, como a melancolia e Saturno:

\footnotetext{
O sombrio demônio astrológico que devora seus filhos, cuja cósmica luta contra uma outra divindade astral pesa sobre o destino da criatura submetida à sua influência, é na obra de Dürer humanizado, e assim se converte na encarnação plástica do homem que trabalha e pensa. (WABURG, 1920, p. 280, apud ALCIDES, 2001, p. 150)
}

Wilhelm Waetzoldt, na biografia que escreveu sobre o artista alemão, avalia a influência literária na obra gráfica de Dürer, em grande parte devida à sua autoformação e natureza imaginativa. A leitura de textos filosóficos, poéticos e astrológicos preenchiam seu conteúdo fantástico, ligado à sua constituição nas crenças e cultura germânica, ao mesmo tempo em que ampliava sua erudição, colocando-o no mesmo nível dos artistas italianos. Do mesmo modo que Giehlow viu traduções imagéticas para poemas de Poliziano. Destacou ainda um constante conflito interior, nascido na dupla natureza de sua formação: de um lado a imaginação popular, sensível à sua condição terrena e temerosa da vontade divina e, de outro, o mundo transformador das descobertas, invenções e revoluções. Waetzoldt acaba concluindo que Dürer viveu o momento em que todas as implicações dos acontecimentos não podiam ser ignoradas, então, transmutou as tensões que pairavam sobre ele em obras que não se isentavam das agitações daquele momento.

Outros textos mais recentes retomam interpretações do tema. Em um deles, Jean Clair (CLAIR, 2005, p. 82-88) propõe uma visão da 
melancolia como a portadora da erudição humanista, que já havia superado sua qualificação medieval. Apesar de utilizar a geometria, a arquitetura e as aplicações da nova ciência da perspectiva, não obstante, permanece a sensação de incapacidade, de incompletude. $O$ conhecimento também impõe limites à razão e leva à uma consciência do limiar de um não saber.

No mesmo livro, Peter-Klaus Schuster ${ }^{11}$ tece uma longa análise de Melencolia I e sua fortuna crítica. Lembrando várias interpretações da gravura já escritas por Warburg, Giehlow, Panofsky e Saxl faz comparações e conclui por uma conciliação entre as diferentes opiniões. Se para Panofsky a gravura traz a cautela advinda da percepção dos limites humanos, que conduz o espírito à astenia paralizante ao reconhecer sua incapacidade para superá-los; para Warburg, traz o reconforto do triunfo do temperamento saturnino diante de seus algozes: abatimento, sombras, loucura. Melencolia I encarna a personificação da vitória das disposições desse temperamento, escritas por Ficino, reunidas na imagem de Dürer.

Schuster também reconhece, em todos os autores, a percepção da ambiguidade e da polissemia características da melancolia, oscilando sempre entre a Virtude e a Fortuna. Sua representação está bastante ligada ao repertório alegórico tanto medieval quanto renascentista: Panofsky a identifica com a acedia, enquanto Warburg evoca o espírito humanista do gênio melancólico, indicando a inscrição da virtude na elevação do melancólico em direção à perfeição divina.

Todas essas disposições apresentadas na alegoria de Dürer a tornaram uma referência importante na arte alemã, reconhecida principalmente durante o Romantismo, quando bem encarna a identidade e a sensibilidade alemã ao longo de sua história, expondo todos os embates que a acompanham em cada momento. Surge, então, o nome de um melancólico célebre, Walter Benjamin, para quem "O único prazer que o melancólico se permite, um prazer intenso, é a alegoria" (SONTAG, 1986, p. 96) ${ }^{12}$.

Para Benjamin, Melencolia I antecipou um tema central do Barroco, a integração da imagem renascentista da melancolia com a da vaidade. $\bigcirc$ saber que vem da ruminação e a ciência que vem da pesquisa se unem em um novo homem.

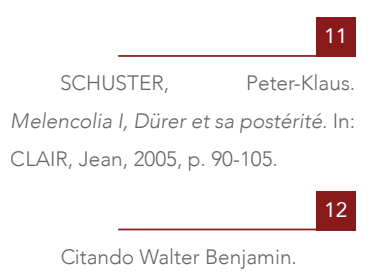

12 
[...] É consistente com esse conceito que em torno do personagem de Albrecht Dürer, na Melancolia, estejam dispersos no chão os utensílios da vida ativa, sem qualquer serventia, como objetos de ruminação. Essa gravura antecipa sob vários aspectos o Barroco [...]. A Renascença investiga o universo e o Barroco, as bibliotecas. Sua meditação tem o livro como correlato[...]. (BENJAMIN, 1984, p. 121)

Partes da gravura e da concepção da melancolia como desespero decorrente de um estado emocional aparecem como um objeto definido, como por exemplo, no quadro de Domenico Feti, La Mélancolie, de 1610, no qual a figura feminina segura um crânio. Assim é o sonho humano: apenas loucura, o homem se tornou divorciado do cosmos. Esse sentimento não era mera afetação, refletia a realidade de uma compreensão evolutiva, especialmente nas artes visuais.

De acordo com Susan Sontag, Walter Benjamin, considerado un triste pelos franceses, quando dizia que "a solidão parecia o único estado apropriado ao homem" (SONTAG, 1986, p. 87) se referia "à solidão da grande metrópole, a atividade do indivíduo que passeia sem destino livre para sonhar, observar, refletir, viajar". Essa multidão, contraditoriamente, é o lugar do anonimato. E essa é uma das características do ser melancólico "a necessidade de estar só - assim como a amargura da própria solidão". A autora traça o perfil do ser melancólico, dizendo que "o trabalho do melancólico é a imersão, a concentração total".

Segundo Sontag, os melancólicos nascem sob o signo de Saturno o planeta dos desvios, astro de revolução lenta...

A influência de Saturno torna as pessoas 'apáticas, indecisas, vagarosas', escreve, em A Origem do Drama Barroco Alemão. A lentidão é uma característica do temperamento melancólico. A falta de jeito é outra e deriva da percepção de um número excessivo de possibilidades, e da não-percepção da própria falta de senso prático (SONTAG, 1986, p. 87.)

Outra característica importante, a polissemia presente na gravura de Dürer, própria do temperamento melancólico, também é um comentário 
recorrente em diferentes autores, desde Aristóteles, que já ressaltara a natureza polimorfa do melancólico.

A bile negra oferece à natureza melancólica todos os estados da embriaguez com todos os seus perigos [...]. O melancólico tem em si, como possíveis, todos os caráteres de todos os homens. O que esclarece prodigiosamente [...] a ideia mesma da criatividade melancólica (PIGEAUD, 1998, p. 13).

Finalmente, é preciso tentar de todas as formas chegar ao mais próximo possível do pensamento de Ficino e Dürer, procurando a essência filosófica que os conduziu, naquela época. Tarefa (im)possível! São outros tempos em um ambiente muito distante. A posição de Schuster mencionada acima é bastante cordata com o ambíguo estado bilioso. Em Melencolia I encontramos toda disposição de Dürer em, de fato, criar uma imagem para o impreciso sentimento saturnino. Aquele que está presente no ideal humanista de superar constantemente os limites da natureza humana, aproximando-se cada vez mais do divino.

\section{Referências}

ALBRECHT Dürer, obras. Disponível em: <www.albrecht-durer.org>. Acesso em: 5 jan. 2014.

ALCIDES, Sérgio. Sob o signo da iconologia: uma exploração do livro Saturno e a melancolia, de R. Klibansky, E. Panofsky e F. Saxl. Topoi, Rio de Janeiro, v. 2, n. 3, p. 131-174, 2001. Disponível em: < www.ppghis.ifcs.ufrj.br/ media/topoi3a5.pdf>. Acesso em: $1^{\circ}$ nov. 2008.

ARISTÓTELES. Problema XXX. Tradução de Elisabete Thamer. Disponível em: <www.ifcs.ufrj.br/ fsantoro/ousia/traducao>. Acesso em: $1^{\circ}$ fev. 2008.

BENJAMIN, Walter. Origem do Drama Barroco Alemão. São Paulo: Brasiliense, 1984. 
BENJAMIN, Walter. Origem do drama trágico alemão. Belo Horizonte: Autêntica, 2011.

BERLINCK, Luciana Chauí. Melancolia e contemporaneidade. Cadernos Espinosianos XVII, São Paulo. Disponível em: <www.ffich.usp.br/df/ espinosianos>. Acesso em: $1^{\circ} \mathrm{fev} .2008$.

BÍBLIA SAGRADA. Velho Testamento. Primeiro livro de Samuel, capítulo 16, versículos 14 - 23. Imprensa Bíblica Brasileira: Rio de Janeiro, 1995.

CLAIR, Jean (Org.). Mèlancolie, génie et folie em occident. Paris: Réunion des Musées Nationaux, Galimmard, 2005.

GINZBURG, Carlo. De A. Warburg a E. Gombrich, notas sobre um problema de método, In: Mitos, emblemas e sinais: morfologia e história. São Paulo: Cia das Letras, 1989. p. 41-93.

KLIBANSKY, R.; PANOFSKY, E.; SAXL, F. Saturno y la melancolia. Madrid: Alianza Editorial, 2004.

MATOS, Olgária. Os arcanos do inteiramente outro: a escola de Frankfurt, a melancolia e a revolução. São Paulo: Brasiliense, 1989.

PANOFSKY, E. Vida y arte de Alberto Durero. Madri: Alianza Forma, 2005.

PIGEAUD, Jackie. Apresentação. ARISTÓTELES. O Homem de Gênio e a Melancolia. O Problema XXX, 1. Rio de Janeiro: Nova Aguilar, 1998.

SCHUSTER, Peter Klaus. Melencolia I Dürer et sa postérité. In: CLAIR, Jean. Mélancolie, génie et folie en Occident. Paris: Réunion des Musées Nationaux; Galimmard, 2005.

SONTAG, Susan. Sob o signo de Saturno. Porto Alegre: LPM Ed., 1986.

WAETZOLDT, Wilhelm. Dürer und seine Zeit. Zurique: Phaidon, 1950. 